OPEN ACCESS

Edited by:

Roberto Angelini,

Swansea University Medical School,

United Kingdom

Reviewed by:

Gregory C. Henderson,

Purdue University, United States

Norbert Stefan,

University of Tübingen, Germany

*Correspondence:

Beate Fuchs

fuchs.beate@fbn-dummerstorf.de

Specialty section:

This article was submitted to Lipid and Fatty Acid Research,

a section of the journal

Frontiers in Physiology

Received: 28 June 2021

Accepted: 21 October 2021

Published: 10 November 2021

Citation:

Engel KM, Schiller J, Galuska CE and Fuchs B (2021) Phospholipases and Reactive Oxygen Species Derived

Lipid Biomarkers in Healthy and Diseased Humans and Animals A Focus on Lysophosphatidylcholine.

Front. Physiol. 12:732319.

doi: 10.3389/fphys.2021.732319

\section{Phospholipases and Reactive Oxygen Species Derived Lipid Biomarkers in Healthy and Diseased Humans and Animals - A Focus on Lysophosphatidylcholine}

\author{
Kathrin M. Engel ${ }^{1}$, Jürgen Schiller ${ }^{1}$, Christina E. Galuska ${ }^{2}$ and Beate Fuchs ${ }^{2 *}$ \\ ${ }^{1}$ Faculty of Medicine, Institute of Medical Physics and Biophysics, University of Leipzig, Leipzig, Germany, ${ }^{2}$ Core Facility \\ Metabolomics, Research Institute for Farm Animal Biology (FBN), Dummerstorf, Germany
}

Phospholipids $(\mathrm{PL})$ are converted into lipid biomarkers by the action of phospholipases and reactive oxygen species (ROS), which are activated or released under certain physiological and pathophysiological conditions. Therefore, the in vivo concentration of such lipid biomarkers [e.g., lysophospholipids (LPLs)] is altered in humans and animals under different conditions such as inflammation, stress, medication, and nutrition. LPLs are particularly interesting because they are known to possess proand anti-inflammatory properties and may be generated by two different pathways: either by the influence of phospholipase $\mathrm{A}_{2}$ or by different reactive oxygen species that are generated in significant amounts under inflammatory conditions. Both lead to the cleavage of unsaturated acyl residues. This review provides a short summary of the mechanisms by which lipid biomarkers are generated under in vitro and in vivo conditions. The focus will be on lysophosphatidylcholine (LPC) because usually, this is the LPL species which occurs in the highest concentration and is, thus, easily detectable by chromatographic and spectroscopic methods. Finally, the effects of lipid biomarkers as signaling molecules and their roles in different human and animal pathologies such as infertility, cancer, atherosclerosis, and aging will be shortly discussed.

Keywords: disease markers, inflammation, lysophospholipids, lysophosphatidylcholine, phospholipids, phospholipase, reactive oxygen species, disease marker

\section{INTRODUCTION - PHOSPHOLIPIDS AS EDUCTS OF RELEVANT PHYSIOLOGICAL MOLECULES}

Phospholipids (PL) constitute an important class of biomolecules, among which glycerophospholipids (GPL) are of high relevance (Law et al., 2019). All GPLs consist of a glycerol backbone, where two hydroxyl groups are esterified with two (often varying) fatty acids. The third hydroxyl group is esterified with phosphoric acid. The resulting molecule is termed "phosphatidic acid" (PA). Via ester condensation with different alcohols such as choline or ethanolamine, phosphatidylcholine (PC), and phosphatidylethanolamine (PE) are generated. These compounds represent the most abundant zwitterionic GPL in mammalian membranes. 
The majority of PLs occurring under in vivo conditions are characterized by a saturated fatty acyl residue in $s n-1$ position, while the second fatty acyl residue is often mono- (e.g., oleic acid), di- (e.g., linoleic acid) or even higher unsaturated (e.g., arachidonic or docosahexaenoic acid, which contain four or six double bonds, respectively). GPLs are converted into lysophospholipids (LPLs) by the action of phospholipases. The reactions catalyzed by these enzymes are illustrated in Figure 1. The released free fatty acids have considerable physiological significance: highly unsaturated fatty acids such as arachidonic acid (C20:4) are very sensitive to oxidation and its metabolic (oxidation) products such as thromboxanes, prostaglandins, or leukotrienes have a considerable biological impact (Johnson et al., 2020).

Both, the LPL as well as the free fatty acid are considered as important molecules with potential messenger functions and destabilize cellular membranes due to their detergent-like character (Hu et al., 2007).

\section{GENERATION OF LYSOPHOSPHOLIPID UNDER THE INFLUENCE OF PHOSPHOLIPASES AND REACTIVE OXYGEN SPECIES}

Phospholipase "A" (PLA) is represented by a group of enzymes that catalyze the hydrolysis of one fatty acyl residue from the glycerol backbone of a PL. By this reaction, a free fatty acid is released and the corresponding LPL is left in the membrane (Peng et al., 2021; Figure 1).

The cleavage of phosphatidylcholine (PC) by $\mathrm{PLA}_{2}$ yields lysophosphatidylcholine (LPC) and free fatty acids, e.g., arachidonic acid, the educt of eicosanoids. The hydrolysis of diacylglycerol (DAG) by DAG lipase at the $s n-1$ position results in 2-arachidonoylglycerol (2-AG) followed by a monoacylglycerol lipase (MAGL)-dependent hydrolysis of 2-AG to generate arachidonic acid and further eicosanoid pathway metabolites. Please note that more degradation products such as lysophosphatidic acid (LPA) (Hosogaya et al., 2008) (LPA) and glycerophosphocholine (GPC) can be produced by other phospholipases as well as reconversion by acyltransferases can take place (Brindley and Bräuer, 2010).

Based on the stereospecificity of the reaction, $\mathrm{PLA}_{1}$ and PLA 2 activities can be differentiated. PLA 1 enzymes generally play a minor role than $\mathrm{PLA}_{2}$ (Richmond and Smith, 2011), although there is increasing evidence that $\mathrm{PLA}_{1}$ activity is underestimated regarding the generation of lysophosphatidylserine (LPS) (Iwata et al., 2021). The prevailing opinion is that LPLs are generated under in vivo conditions by the release and/or activation of $\mathrm{PLA}_{2}$ that is particularly present in neutrophilic granulocytes, important cellular mediators of inflammation. However, neutrophils do not only secrete $\mathrm{PLA}_{2}$, but are also capable of generating reactive oxygen species (ROS; PérezFigueroa et al., 2021). All ROS are derived from atmospheric air oxygen, which is converted in a set of reactions into $\mathrm{H}_{2} \mathrm{O}_{2}$. This is the precursor for the generation of further, much more reactive species, for instance, hydroxyl radicals $\left(\mathrm{HO}^{\bullet}\right)$. Despite the high reactivity of $\mathrm{HO}^{\bullet}$, that reacts diffusion-controlled with nearly all organic molecules, another ROS seems to be responsible for the increased levels of LPC under pathological conditions: hypochlorous acid (HOCl; Schröter and Schiller, 2016). $\mathrm{HOCl}$ is generated under in vivo conditions from $\mathrm{H}_{2} \mathrm{O}_{2}$ and $\mathrm{Cl}^{-}$ions under catalysis of myeloperoxidase (MPO; Kargapolova et al., 2021):

$$
\mathrm{H}_{2} \mathrm{O}_{2}+\mathrm{Cl}^{-} \rightarrow \mathrm{HOCl}+\mathrm{HO}^{-}
$$

Myeloperoxidase is nearly exclusively found in neutrophils, where it amounts to approximately 5\% of the total protein content (Schröter and Schiller, 2016). As the number of neutrophilic granulocytes increases massively under inflammatory conditions, the roles of MPO and its products are obvious (Arnhold, 2020). In vitro, it could be shown that LPC is also generated from isolated $\mathrm{PC}$ by the reaction with $\mathrm{HOCl}$ (Arnhold et al., 2002).

\section{METHODS OF LYSOPHOSPHOLIPID DETERMINATIONS}

Methods of LPL determinations often rely on, for instance, UV-, fluorescence, or ESR Spectroscopy, radioactivity or capillary electrophoresis. These methods detect mainly the related phospholipase activities, need prior labeling and/or do not give detailed structural information of the generated LPL. We will focus here on NMR (particularly ${ }^{31} \mathrm{P}$ and ${ }^{1} \mathrm{H}$ NMR), chromatography (mainly HPLC and TLC) and mass spectrometry as these methods overcome many disadvantages of the methods mentioned above - in particular, they do not require any specific labels. The advantages and drawbacks as well as details of the individual techniques are compared in Table 1.

It is important to note, that LPC can be generated from PC even under in vitro conditions. That is, even solutions of PC that are meant to be pure still often contain small amounts of LPC and the LPC moiety increases during storage (HernandezCaselles et al., 1990). Of course, the amount of detected LPC is also influenced by the applied extraction protocol because LPC is much more polar than other lipids. MALDI MS has the considerable advantage that LPC may also be determined from native samples, i.e., without the necessity of sample extraction that may result in the LPL loss. These aspects were recently discussed by Ditz and Fuchs (2018) and have already been comprehensively reviewed by Petković et al. (2005).

\section{LYSOPHOSPHOLIPID AS INFLAMMATION AND DISEASE MARKERS}

Lysophospholipid (LPL) such as LPC, LPA, sphingosine1-phosphate (S1P), LPS (Kurano et al., 2015), and lysophosphatidylinositol (LPI) have pronounced effects on 


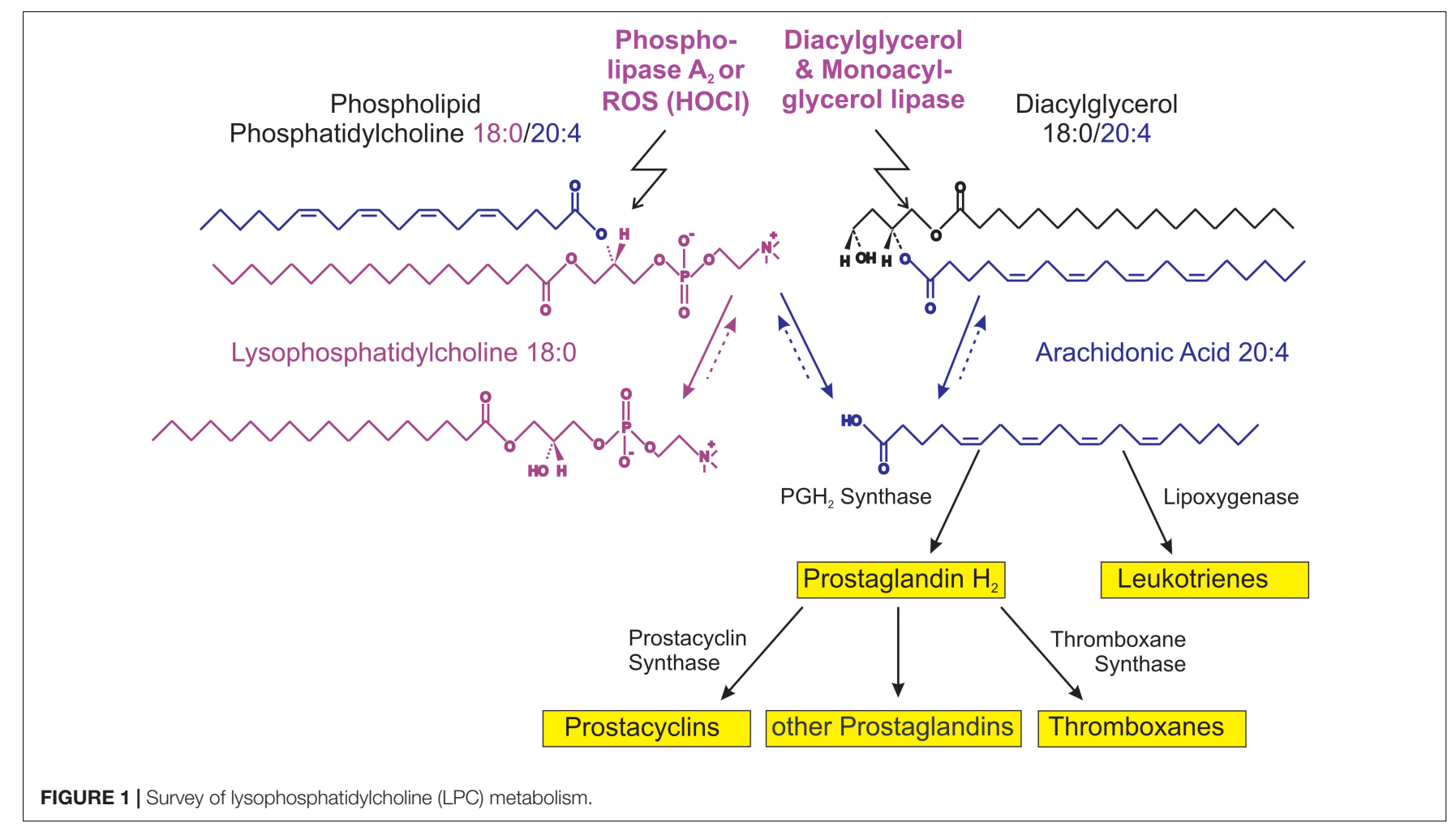

diverse cell lines and the immunological effects induced by these compounds have already been reviewed (Xu et al., 2013). For some LPL, such as LPI and LPS signaling via G protein-coupled receptors (GPCR) has been described and was comprehensively reviewed by Tan et al. (2020). Even though the possibility of GPCR-mediated function of LPC has been pointed out, there is currently no GPCR for LPC binding known (Makide et al., 2014). Despite many studies revealed pro-inflammatory effects of LPL - such as LPC as key marker that is positively associated with cardiovascular and neurodegenerative diseases - there are also research articles demonstrating anti-inflammatory effects of these compounds, making findings controversial (Knuplez and Marsche, 2020). This controversial behavior can be explained by the in vivo generation of two different compounds: LPL and free fatty acids. In inflammation, the released free fatty acid is often arachidonic acid that is readily converted into compounds with immunomodulatory effects. Furthermore, LPC is a precursor of extracellular LPA, an important lipid mediator and modulator of neuronal function (Brindley and Bräuer, 2010). LPA is produced from LPC by autotaxin and is therefore a direct executioner of LPC (Hosogaya et al., 2008; Yatomi et al., 2018). However, the concentration of LPA in body fluids and tissues is always much lower (normally about two orders of magnitude) compared to LPC. In a nutshell, both, the generation of LPL and the formation of arachidonate-derived metabolites must be inhibited for pharmacological effects (Sun et al., 2014).

There is one interesting study that illustrates the potential "marker quality" of LPC: it was shown that horse sera with a high LPC content are not useful for cell experiments because they have deleterious effects on cell growth. This suits the finding that horse sera with moderate amounts of LPC were also characterized by low levels of inflammatory eicosanoids (Ditz et al., 2019).

\section{Lysophosphatidylcholine Under Inflammation and Stress}

The concentration of LPC increases under inflammatory conditions. This has been shown, for instance, in joint fluids from rheumatoid arthritis patients (Fuchs et al., 2005) or atherosclerosis patients (Matsumoto et al., 2007). Under certain conditions, however, the opposite was observed: plasma LPC showed an inverse relationship with cardiovascular diseases (Ganna et al., 2014). In other studies, the LPC/PC ratio in plasma as well as cerebrospinal fluid from patients with Alzheimer's disease decreased (Lin et al., 2017). Unfortunately, all these studies were methodologically different and, thus, the comparability is poor.

Lysophosphatidylcholine and LPE levels rise considerably in human inflammatory liver tissue (Schober et al., 2009). Particularly, LPC could serve as a biomarker in fatty liver disease. However, it is known that also a metabolically healthy fatty liver exists (Stefan et al., 2019). The comparison of molecule pattern of plasma from insulin-sensitive and insulinresistant human subjects have shown that particularly LPCs are capable to distinguish benign and malignant non-alcoholic fatty liver (Lehmann et al., 2013) and mechanisms involved in this process, e.g., pro-inflammatory signaling ( $v i a$ regulation of LPC acyltransferase) were discussed. Similarly, in studies with nonalcoholic steatohepatitis in mice major reductions in LPC 16:0, 18:0 and 18:1 were identified (Tanaka et al., 2012). 
TABLE 1 | Survey of selected techniques of lysophospholipid (LPL) analysis.

\begin{tabular}{|c|c|c|c|c|}
\hline & Principle & Advantages & Drawbacks & Remarks \\
\hline $\begin{array}{l}\text { High-performance } \\
\text { liquid } \\
\text { chromatography } \\
\text { (HPLC) }\end{array}$ & $\begin{array}{l}\text { Separation on a "stationary } \\
\text { phase" under high pressure by } \\
\text { elution with solvents of different } \\
\text { polarities; "reversed" phase is } \\
\text { more common than normal } \\
\text { phase. }\end{array}$ & $\begin{array}{l}\text { Can be standardized; protocols } \\
\text { are available for many analytes; } \\
\text { coupling with MS is well } \\
\text { established - although } \\
\text { detection by UV or light } \\
\text { scattering is still widely used; } \\
\text { preparative HPLC is possible. }\end{array}$ & $\begin{array}{l}\text { Requires experienced } \\
\text { operators; detection of } \\
\text { saturated lipids (lack of UV } \\
\text { absorptions) is difficult; } \\
\text { post-column derivatization is } \\
\text { time-consuming. }\end{array}$ & $\begin{array}{l}\text { Routine method in many } \\
\text { laboratories; "fine-tuning" of the } \\
\text { mobile phase to the relevant } \\
\text { sample is normally required; a } \\
\text { timely review with the focus on } \\
\text { liposomes and the detection of } \\
\text { LPC as impurity is available in } \\
\text { de Magalhães Benedetti et al. } \\
\text { (2020). }\end{array}$ \\
\hline $\begin{array}{l}\text { Thin-layer } \\
\text { chromatography } \\
\text { (TLC) }\end{array}$ & $\begin{array}{l}\text { Separation on a stationary } \\
\text { phase (normally silica gel) due } \\
\text { to polarity differences of the } \\
\text { analytes; different } \\
\text { modifications/polarities of the } \\
\text { stationary phase are } \\
\text { commercially available }\end{array}$ & $\begin{array}{l}\text { Inexpensive and fast; many } \\
\text { samples can be simultaneously } \\
\text { analyzed; stainings with } \\
\text { different properties } \\
\text { (non-covalent, covalent binding, } \\
\text { UV, fluorenscence detection) } \\
\text { can be used for detection. }\end{array}$ & $\begin{array}{l}\text { Oxidation (of unsaturated LPL } \\
\text { species) may occur during the } \\
\text { run; resolving LPL with different } \\
\text { acyl residues is difficult; less } \\
\text { sensitive compared to MS. }\end{array}$ & $\begin{array}{l}\text { Often used as initial method if a } \\
\text { complex lipid mixture has to be } \\
\text { analyzed in detail; TLC-based } \\
\text { lipid analysis is still common } \\
\text { (Adibi et al., 2018). }\end{array}$ \\
\hline ESI MS & $\begin{array}{l}\text { lons are generated from } \\
\text { charged droplets. }\end{array}$ & $\begin{array}{l}\text { "very soft" ionization method; } \\
\text { little analyte fragmentation; } \\
\text { quantification possible in the } \\
\text { presence of a suitable internal } \\
\text { standard. }\end{array}$ & $\begin{array}{l}\text { Ion suppression may occur; } \\
\text { strongly affected by sample } \\
\text { impurities as well as the } \\
\text { composition of the solvent. }\end{array}$ & $\begin{array}{l}\text { ESI MS is already in clinical use } \\
\text { since metabolite determination } \\
\text { by MS is often cheaper than } \\
\text { other methods (Liebisch et al., } \\
\text { 2002). }\end{array}$ \\
\hline MALDI MS & $\begin{array}{l}\text { lons are generated by laser } \\
\text { irradiation of a matrix/analyte } \\
\text { cocrystal }\end{array}$ & $\begin{array}{l}\text { "soft" ionization method; little } \\
\text { analyte fragmentation; very little } \\
\text { sample pretreatment and } \\
\text { purification required. }\end{array}$ & $\begin{array}{l}\text { Ion suppression may occur; } \\
\text { obtaining quantitative data is } \\
\text { difficult. }\end{array}$ & $\begin{array}{l}\text { PC/LPC ratios are often given } \\
\text { which can be calculated } \\
\text { without internal standards } \\
\text { (Bresler et al., 2011). }\end{array}$ \\
\hline${ }^{1} \mathrm{H} \mathrm{NMR}$ & $\begin{array}{l}\text { Differences in electron densities } \\
\text { lead to different chemical shifts } \\
\text { of the observed nucleus within } \\
\text { a given compound }\end{array}$ & $\begin{array}{l}\text { Basically all lipids are } \\
\text { detectable; isomers can be } \\
\text { differentiated without the need } \\
\text { of previous separation; spectra } \\
\text { exhibit quantitative information. }\end{array}$ & $\begin{array}{l}\text { Analyses of mixtures lead to } \\
\text { complex spectra; need of } \\
\text { deuterated solvents; expensive } \\
\text { equipment; differences in the } \\
\text { fatty acyl compositions can } \\
\text { hardly be resolved. }\end{array}$ & $\begin{array}{l}\text { One characteristic functional } \\
\text { group (the quaternary ammonia } \\
\text { group) is used as the sensor to } \\
\text { detect the different classes; } \\
\text { high magnetic field strengths } \\
\text { are required to resolve PC, LPC } \\
\text { and SM (same headgroups) } \\
\text { (Soininen et al., 2007). }\end{array}$ \\
\hline${ }^{31} \mathrm{P}$ NMR & $\begin{array}{l}\text { The different chemical } \\
\text { environment renders each P } \\
\text { atom a characteristic chemical } \\
\text { shift. }\end{array}$ & $\begin{array}{l}\text { Direct absolute quantitation is } \\
\text { possible; isomeric lipids can be } \\
\text { differentiated. }\end{array}$ & $\begin{array}{l}\text { Limited sensitivity (order of } \\
\text { magnitude less than MS); } \\
\text { requires high amounts of } \\
\text { sample; expensive equipment. }\end{array}$ & $\begin{array}{l}\text { Detergents or solvent mixtures } \\
\text { have to be used in order to } \\
\text { suppress the aggregation of } \\
\text { phospholipids; acyl migration } \\
\text { may falsify the results (Sugasini } \\
\text { and Subbaiah, 2017); has been } \\
\text { recently reviewed: (Li et al., } \\
\text { 2017). }\end{array}$ \\
\hline
\end{tabular}

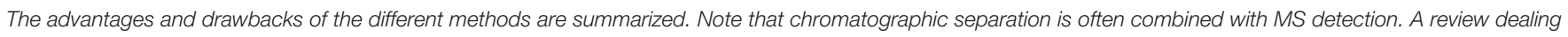
with selected methods is available in Helmerich and Koehler (2003).

It could also be shown that LPC enhances the generation of superoxide anion radicals $\left(\mathrm{O}_{2}{ }^{\bullet-}\right)$ as well as $\mathrm{H}_{2} \mathrm{O}_{2}$ (Englberger et al., 1987), i.e., LPC may trigger the generation of even stronger ROS such as $\mathrm{HO}^{\bullet}$ or $\mathrm{HOCl}$. Similar observations were made for lymphocytes, at which the presence of LPC led to an increased number of apoptotic cells. However, it is not known whether these studies are relevant under in vivo conditions. In vivo, there is a huge amount of proteins with high affinity for LPC, e.g., albumin and lipoproteins. Thus, the amount of physiologically available LPC may vary considerably. Anyway, LPC normally does not accumulate in the body because different mechanisms limit the elevation of LPC concentrations: (I) the re-acylation of LPC to PC, (II) the degradation of LPC to GPC by the cleavage of the fatty acyl residue in the $s n-1$ position by lysophospholipases. GPC lacks both acyl residues and is, thus, soluble in water. An overview of the PC- and LPC-related pathways was provided by Fuchs et al. (2012).

Despite the many open questions, targeting LPC and its metabolic pathways might be a prospective treatment strategy of inflammatory diseases (Liu et al., 2020).

\section{Lysophospholipid in Fertility and Infertility}

Male gametes are perhaps the most important cells at which LPL are known to have significant impact. The related process is called "capacitation": mammalian spermatozoa undergo a variety of physiological events, which make them ready for fertilization, i.e., the fusion between the sperm and the female oocyte. 
Ye (2008) reviewed the physiological functions of LPL (particularly LPA and S1P) in reproduction as well as potential pathological side effects. LPC has been shown to have an impact on human corporal smooth muscle cells, and therefore, might lead to an impaired penile function through TPR channels (So et al., 2005). Furthermore, it is known since many years that LPC is capable of triggering sperm acrosomal exocytosis, an important event that primes spermatozoa for successful fertilization (Ehrenwald et al., 1988). Roldan and Shi (2007) examined the action of $\mathrm{PLA}_{2}$ and its role for successful fertilization. There are two obvious functions of the generated LPL: on the one hand, they represent second messengers for cellular signaling. On the other hand, they act as detergents and destabilize the membranes by changing their biophysical properties. Despite the obvious physiological role of $\mathrm{PLA}_{2}$ activation, spermatozoa avoid premature destabilization and, thus, a carefully controlled equilibrium between LPL generation and its reacylation into the corresponding PL must exist. Deviations from normal conditions may otherwise lead to pathological situations, so that an enhanced sperm LPL concentration is presumably indicative of a reduced fertilizing potential. There is evidence that the LPC content reciprocally correlates with the sperm quality of human sperm (Roldan and Shi, 2007). Using magnetic assisted cell sorting (MACS) to separate intact and apoptotic (annexin $\mathrm{V}$ positive) spermatozoa, it was shown that the LPC content is much higher in the apoptotic sperm (Glander et al., 2002). Although it is not yet clear whether the observed effect is triggered by an enhanced generation of ROS or an elevated PLA 2 activity, there are many indications that oxidative stress has a pronounced impact on sperm physiology (Takeshima et al., 2020). For instance, sperm from extremely obese men are characterized by an enhanced LPC content. This correlates with a reduced fertilizing capacity of these men (Pyttel et al., 2012).

Thus, LPC might represent an interesting "marker" molecule in fertility that definitely is worth of further investigations because it has a considerable advantage: in comparison to proteins, LPC is a non-specific marker that could be useful for human as well as animal spermatozoa (Nimptsch et al., 2014).

\section{Lysophosphatidylcholine and Aging}

It is known that lipids play a role in lifespan regulation and age-related diseases (de Diego et al., 2019). Very recently, the use of lipidomics to age-related musculoskeletal disorders was reviewed (Mo et al., 2021). Siddharth et al. (2017) monitored changes of serum lipids in aged mice with a sarcopenic phenotype and found that levels of LPC 20:5 and LPC 20:3 were reduced although an explanation of the occurrence of these unusual fatty acids was not provided. In humans blood LPC levels tend to decrease with age: low plasma levels of LPC are associated with impaired mitochondrial oxidative capacity in adults (Semba et al., 2019). Lower levels of LPC 18:2 were shown to be predictive of memory impairment and enable the prediction of a greater decline of gait speed in the elderly (Gonzalez-Freire et al., 2019).

Patients with cancer, an age-related disease, exhibit a decreased LPC concentration in plasma (Taylor et al., 2007).
Similarly, Kim et al. (2014) found that the LPC 24:0 levels in aged mice were lower compared to young mice. Although no explanation of the occurrence of this less common organic residue (lignoceric acid) is provided, the authors conclude that the ratios of the individual metabolites PC and LPC could serve as potential biomarkers for aging and age-related diseases. In contrast, there are also studies showing that during aging the levels of LPC increase - in particular in patients suffering from Alzheimer's disease (Dorninger et al., 2018). Although not yet carefully studied, LPC seems to enhance oxidative stress via the 5-lipoxygenase pathway in rat aorta during aging (Zou et al., 2009). This might foster further pharmacological studies because lipoxygenase is one interesting target for many drugs.

\section{Lysophosphatidylcholine Under Medication, Nutrition, and Pharmacological Aspects}

The normal concentration of LPC in plasma is significant (about 200-300 $\mu \mathrm{M}$ ) - with most LPC bound to albumin and lipoproteins (Kishimoto et al., 2002). Anyway, LPCtreatment of mice induces enhanced phagocytic activity of macrophages (Lee et al., 2018). Intracutaneous injection of LPC in healthy volunteers similarly elicited acute inflammation with the accumulation of $\mathrm{T}$ lymphocytes, monocytes, and neutrophils (Murugesan et al., 2003). Direct pro-inflammatory and atherogenic effects of LPC have become apparent over the past 30 years. Nowadays, there is increasing evidence that LPC has also anti-inflammatory properties, making its profile more complex than initially assumed (Schilke et al., 2020). These controversial effects of LPC are presumably caused by differences in length and/or the saturation state of the fatty acyl chain (Tan et al., 2020). Additionally, different functional effects of LPC may also be due to different moieties of the free and the albumin-bound LPC (Mehta, 2005).

Dietary polar lipids are relevant for the cognitive development and are distributed throughout the body by lipoproteins (Zheng et al., 2019). Lipids play an unequivocal active part in the acceptability, flavor, and perception of foods and may be beneficial for health - or lead to various pathologies (Meynier and Genot, 2017). Finally, LPC is used in animal nutrition to improve animal performance, i.e., to favor the digestion of food and the release of nutrients from the diet (Wealleans et al., 2020).

As LPC concentration is elevated in many pathologies, different attempts were undertaken to decrease the LPC concentration in vivo. Because of the obvious contribution of $\mathrm{PLA}_{2}$, this has raised interest for pharmacologically-active substances capable of inhibiting $\mathrm{PLA}_{2}$ activity (Yalagala et al., 2019; Frangieh et al., 2021). However, PLA 2 activation does not only result in LPC generation but also in arachidonate-derived free radical intermediates (Sun et al., 2014) and further ROS. Therefore, a single drug molecule with both - anti-oxidative and $\mathrm{PLA}_{2}$ inhibitory activity - would be useful since it could inhibit $\mathrm{PLA}_{2}$ activity and simultaneously scavenge free radicals and lipid peroxides which are released during C20:4 metabolism. 


\section{CONCLUDING REMARKS}

Lysophospholipids represent lipid molecules with a Janus-faced character: on the one hand, LPL are important signaling molecules that are required for physiological processes, such as successful fertilization or proper memory function. On the other hand, their in vivo concentrations has to be carefully controlled, e.g., a disturbance of the equilibrium between LPC generation and re-acylation can lead to severe pathological conditions. The focus of this review is on LPC and this is also true for previous studies. This is, at least partially, caused by the fact that this LPL can be most sensitively detected. This can be achieved with low resolution mass spectrometers. Furthermore, LPC is a comparably stable compound, that does not react with other compounds that is again an excellent property for its successful determination. It remains to be elucidated whether and which LPL are useful and reliable biomarkers of (inflammatory)

\section{REFERENCES}

Adibi, S. S., Alcorn, J. L., Ono, K., and Lichtenberger, L. M. (2018). Gender and smoking correlations of surfactant lipids and proteins in the saliva of dental patients. J. Dent. Maxillofac. 1, 67-70.

Arnhold, J. (2020). The dual role of myeloperoxidase in immune response. Int. J. Mol. Sci. 21:8057.

Arnhold, J., Osipov, A. N., Spalteholz, H., Panasenko, O. M., and Schiller, J. (2002). Formation of lysophospholipids from unsaturated phosphatidylcholines under the influence of hypochlorous acid. Biochim. Biophys. Acta 1572, 91-100.

Bresler, K., Pyttel, S., Paasch, U., and Schiller, J. (2011). Parameters affecting the accuracy of the MALDI-TOF MS determination of the phosphatidylcholine/lysophosphatidylcholine (PC/LPC) ratio as potential marker of spermatozoa quality. Chem. Phys. Lipids 164, 696-702. doi: 10.1016/j.chemphyslip.2011.07.006

Brindley, D. N., and Bräuer, A. U. (2010). "Lipid mediators and modulators of neural function: lysophosphatidate and lysolipids," in Handbook of Neurochemistry and Molecular Neurobiology, eds A. Lajtha, G. Tettamanti, and G. Goracci (Boston, MA: Springer), 289-310. doi: 10.1007/978-0-387-303789_12

de Diego, I., Peleg, S., and Fuchs, B. (2019). The role of lipids in aging-related metabolic changes. Chem. Phys. Lipids 222, 59-69. doi: 10.1016/j.chemphyslip. 2019.05.005

de Magalhães Benedetti, N. I. G., Veloso, D. F. M. C., Nascimento, Z. L., Diniz, D. G. A., Maione-Silva, L., and Lima, E. M. (2020). A reliable HPLC-ELSD method for determination of cholesterol, phosphatidylcholine, lysophosphatidylcholine content and the stability of a liposomal formulation. Curr. Pharm. Anal. 16, 623-632. doi: 10.2174/157341291566619061809 2211

Ditz, T., and Fuchs, B. (2018). Determination of the phosphatidylcholine/lysophosphatidylcholine ratio in intact serum by matrixassisted laser desorption/ionization mass spectrometry with prior enzymatic Albumin digestion. Lipids 53, 971-977. doi: 10.1002/lipd.12106

Ditz, T., Schnapka-Hille, L., Noack, N., Dorow, J., Ceglarek, U., Niederwieser, D., et al. (2019). Phospholipase A2 products predict the hematopoietic support capacity of horse serum. Differentiation 105, 27-32. doi: 10.1016/j.diff.2018.12. 002

Dorninger, F., Moser, A. B., Kou, J., Wiesinger, C., Forss-Petter, S., Gleiss, A., et al. (2018). Alterations in the plasma levels of specific choline phospholipids in Alzheimer's disease mimic accelerated aging. J. Alzheimers Dis. 62, 841-854. doi: 10.3233/JAD-171036

Ehrenwald, E., Parks, J. E., and Foote, R. H. (1988). Cholesterol efflux from bovine sperm. I. Induction of the acrosome reaction with lysophosphatidylcholine after reducing sperm cholesterol. Gamete Res. 20, 145-157. doi: 10.1002/mrd. 1120200205 diseases. Contradicting effects of LPC observed in experimental models and patient samples could be due to differences in saturation and/or length of the fatty acyl chain.

\section{AUTHOR CONTRIBUTIONS}

JS wrote chapter 3 including Table 1. KE wrote chapter 4.2. BF wrote chapter 2 including Figure 1 and chapter 4.3. CG wrote chapter 4.4. All authors contributed to the other chapters, abstract, introduction, and conclusions.

\section{FUNDING}

This work was supported by the German Research Council (DFG Schi 476/19-1 and SFB 1052, Project Z3).

Englberger, W., Bitter-Suermann, D., and Hadding, U. (1987). Influence of lysophospholipids and PAF on the oxidative burst of PMNL. Int. J. Immunopharmacol. 9, 275-282. doi: 10.1016/0192-0561(87)9 0051-8

Frangieh, J., Rima, M., Fajloun, Z., Henrion, D., Sabatier, J. M., Legros, C., et al. (2021). Snake venom components: tools and cures to target cardiovascular diseases. Molecules 26:2223. doi: 10.3390/molecules26082223

Fuchs, B., Muller, K., Paasch, U., and Schiller, J. (2012). Lysophospholipids: potential markers of diseases and infertility? Mini-Rev. Med. Chem. 12, 74-86. doi: $10.2174 / 138955712798868931$

Fuchs, B., Schiller, J., Wagner, U., Häntzschel, H., and Arnold, K. (2005). The phosphatidylcholine/lysophosphatidylcholine ratio in human plasma is an indicator of the severity of rheumatoid arthritis: investigations by 31P NMR and MALDI-TOF MS. Clin. Biochem. 38, 925-933. doi: 10.1016/j.clinbiochem. 2005.06.006

Ganna, A., Salihovic, S., Sundström, J., Broeckling, C. D., Hedman, A. K., Magnusson, P. K., et al. (2014). Large-scale metabolomic profiling identifies novel biomarkers for incident coronary heart disease. PLoS Genet. 10:e1004801. doi: 10.1371/journal.pgen.1004801

Glander, H. J., Schiller, J., Süss, R., Paasch, U., Grunewald, S., and Arnhold, J. (2002). Deterioration of spermatozoal plasma membrane is associated with an increase of sperm lyso-phosphatidylcholines. Andrologia 34, 360-366. doi: 10.1046/j.1439-0272.2002.00508.x

Gonzalez-Freire, M., Moaddel, R., Sun, K., Fabbri, E., Zhang, P., Khadeer, M., et al. (2019). Targeted metabolomics shows low plasma lysophosphatidylcholine 18:2 predicts greater decline of gait speed in older adults: the Baltimore longitudinal study of aging. J. Gerontol. A 74, 62-67. doi: 10.1093/gerona/ gly100

Helmerich, G., and Koehler, P. (2003). Comparison of methods for the quantitative determination of phospholipids in lecithins and flour improvers. J. Agric. Food Chem. 51, 6645-6651.

Hernandez-Caselles, T., Villalain, J., and Gomez-Fernandez, J. C. (1990). Stability of liposomes on long-term storage. J. Pharm. Pharmacol. 42, 397-400. doi: 10.1111/j.2042-7158.1990.tb06578.x

Hosogaya, S., Yatomi, Y., Nakamura, K., Ohkawa, R., Okubo, S., Yokota, H., et al. (2008). Measurement of plasma lysophosphatidic acid concentration in healthy subjects: strong correlation with lysophospholipase D activity. Annal. Clin. Biochem. 45, 364-368.

Hu, J. S., Li, Y. B., Wang, J. W., Sun, L., and Zhang, G. J. (2007). Mechanism of lysophosphatidylcholine-induced lysosome destabilization. J. Membr. Biol. 215, $27-35$.

Iwata, Y., Kitajima, S., Yamahana, J., Shimomura, S., Yoneda-Nakagawa, S., Sakai, N., et al. (2021). Higher serum levels of autotaxin and phosphatidylserinespecific phospholipase A1 in patients with lupus nephritis. Int. J. Rheum. Dis. 24, 231-239. doi: 10.1111/1756-185X.14031 
Johnson, A. M., Kleczko, E. K., and Nemenoff, R. A. (2020). Eicosanoids in cancer: new roles in immunoregulation. Front. Pharmacol. 11:595498. doi: 10.3389/ fphar.2020.595498

Kargapolova, Y., Geißen, S., Zheng, R., Baldus, S., Winkels, H., and Adam, M. (2021). The enzymatic and non-enzymatic function of myeloperoxidase (MPO) in inflammatory communication. Antioxidants (Basel) 10:562. doi: 10.3390/ antiox 10040562

Kim, S., Cheon, H. S., Song, J. C., Yun, S. M., Park, S. I., and Jeon, J. P. (2014). Aging-related changes in mouse serum glycerophospholipid profiles. Osong. Public Health Res. Perspect. 5, 345-350. doi: 10.1016/j.phrp.2014.10.002

Kishimoto, T., Soda, Y., Matsuyama, Y., and Mizuno, K. (2002). An enzymatic assay for lysophosphatidylcholine concentration in human serum and plasma. Clin. Biochem. 35, 411-416. doi: 10.1016/s0009-9120(02)00327-2

Knuplez, E., and Marsche, G. (2020). An updated review of pro- and antiInflammatory properties of plasma lysophosphatidylcholines in the vascular system. Int. J. Mol. Sci. 21:4501. doi: 10.3390/ijms21124501

Kurano, M., Dohi, T., Nojiri, T., Kobayashi, T., Hirowatari, Y., Inoue, A., et al. (2015). Blood levels of serotonin are specifically correlated with plasma lysophosphatidylserine among the glycero-lysophospholipids. BBA Clin. 4, 92-98. doi: 10.1016/j.bbacli.2015.08.003

Law, S. H., Chan, M. L., Marathe, G. K., Parveen, F., Chen, C. H., and Ke, L. Y. (2019). An updated review of lysophosphatidylcholine metabolism in human diseases. Int. J. Mol. Sci. 20:1149. doi: 10.3390/ijms20051149

Lee, H. J., Ko, H. J., Song, D. K., and Jung, Y. J. (2018). Lysophosphatidylcholine promotes phagosome maturation and regulates inflammatory mediator production through the protein kinase A-phosphatidylinositol 3?kinase-p38 mitogen-activated protein kinase signaling pathway during Mycobacterium tuberculosis infection in mouse macrophages. Front. Immunol. 9:920. doi: 10. 3389/fimmu.2018.00920

Lehmann, R., Franken, H., Dammeier, S., Rosenbaum, L., Kantartzis, K., Peter, A., et al. (2013). Circulating lysophosphatidylcholines are markers of a metabolically benign nonalcoholic fatty liver. Diab. Care 36, 2331-2338. doi: $10.2337 / \mathrm{dc} 12-1760$

Li, J., Vosegaard, T., and Guo, Z. (2017). Applications of nuclear magnetic resonance in lipid analyses: an emerging powerful tool for lipidomics studies. Prog. Lipid. Res. 68, 37-56. doi: 10.1016/j.plipres.2017. 09.003

Liebisch, G., Drobnik, W., Lieser, B., and Schmitz, G. (2002). High-throughput quantification of lysophosphatidylcholine by electrospray ionization tandem mass spectrometry. Clin. Chem. 48, 2217-2224. doi: 10.1093/clinchem/48.12. 2217

Lin, W., Zhang, J., Liu, Y., Wu, R., Yang, H., Hu, X., et al. (2017). Studies on diagnostic biomarkers and therapeutic mechanism of Alzheimer's disease through metabolomics and hippocampal proteomics. Eur. J. Pharm. Sci. 105, 119-126. doi: 10.1016/j.ejps.2017.05.003

Liu, P., Zhu, W., Chen, C., Yan, B., Zhu, L., Chen, X., et al. (2020). The mechanisms of lysophosphatidylcholine in the development of diseases. Life Sci. 247:117443. doi: 10.1016/j.lfs.2020.117443

Makide, K., Uwamizu, A., Shinjo, Y., Ishiguro, J., Okutani, M., Inoue, A., et al. (2014). Novel lysophosphoplipid receptors: their structure and function. J. Lipid Res. 55, 1986-1995. doi: 10.1194/jlr.R046920

Matsumoto, T., Kobayashi, T., and Kamata, K. (2007). Role of lysophosphatidylcholine (LPC) in atherosclerosis. Curr. Med. Chem. 14, 3209-3220. doi: 10.2174/092986707782793899

Mehta, D. (2005). Lysophosphatidylcholine: an enigmatic lysolipid. Am. J. Physiol. Lung Cell. Mol. Physiol. 289, L174-L175. doi: 10.1152/ajplung.00165.2005

Meynier, A., and Genot, C. (2017). Molecular and structural organization of lipids in foods: their fate during digestion and impact in nutrition. OCL 24:D202. doi: $10.1051 /$ ocl $/ 2017006$

Mo, C., Du, Y., and O'Connell, T. M. (2021). Applications of lipidomics to agerelated musculoskeletal disorders. Curr. Osteoporos. Rep. 19, 151-157. doi: 10. 1007/s11914-021-00656-0

Murugesan, G., Sandhya Rani, M. R., Gerber, C. E., Mukhopadhyay, C., Ransohoff, R. M., Chisolm, G. M., et al. (2003). Lysophosphatidylcholine regulates human microvascular endothelial cell expression of chemokines. J. Mol. Cell. Cardiol. 35, 1375-1384. doi: 10.1016/j.yjmcc.2003.08.004

Nimptsch, A., Pyttel, S., Paasch, U., Mohr, C., Heinrich, J. M., and Schiller, J. (2014). A MALDI MS investigation of the lysophosphatidylcholine/phosphatidylcholine ratio in human spermatozoa and erythrocytes as a useful fertility marker. Lipids 49, 287-293. doi: 10.1007/s11745-013-3870-7

Peng, Z., Chang, Y., Fan, J., Ji, W., and Su, C. (2021). Phospholipase A2 superfamily in cancer. Cancer Lett. 497, 165-177. doi: 10.1016/j.canlet.2020.10.021

Pérez-Figueroa, E., Álvarez-Carrasco, P., Ortega, E., and Maldonado-Bernal, C. (2021). Neutrophils: many ways to die. Front. Immunol. 12:631821. doi: 10. 3389/fimmu.2021.631821

Petković, M., Schiller, J., Müller, J., Leßig, J., Fuchs, B., Müller, M., et al. (2005). Applications of mass spectrometric methods for investigations of kinetic properties of phospholipases. Recent Res. Devel. Lipids 8, 53-94.

Pyttel, S., Zschörnig, K., Nimptsch, A., Paasch, U., and Schiller, J. (2012). Enhanced lysophosphatidylcholine and sphingomyelin contents are characteristic of spermatozoa from obese men - A MALDI mass spectrometric study. Chem. Phys. Lipids 165, 861-865. doi: 10.1016/j.chemphyslip.2012.11.001

Richmond, G. S., and Smith, T. K. (2011). Phospholipases A1. Int. J. Mol. Sci. 12, 588-612. doi: 10.3390/ijms12010588

Roldan, E. R., and Shi, Q. X. (2007). Sperm phospholipases and acrosomal exocytosis. Front. Biosci. 12:89-104. doi: 10.2741/2050

Semba, R. D., Zhang, P., Adelnia, F., Sun, K., Gonzalez-Freire, M., Salem Jr, N., et al. (2019). Low plasma lysophosphatidylcholines are associated with impaired mitochondrial oxidative capacity in adults in the Baltimore Longitudinal Study of Aging. Aging Cell 18:e12915. doi: 10.1111/acel.12915

Schilke, R. M., Blackburn, C. M. R., Bamgbose, T. T., and Woolard, M. D. (2020). Interface of phospholipase activity,I mmune cell function, and atherosclerosis. Biomolecules 10:1449. doi: 10.3390/biom10101449

Schober, C., Schiller, J., Pinker, J., Hengstler, J. G., and Fuchs, B. (2009). Lysophosphatidylethanolamine is - in contrast to - choline - generated under in vivo conditions exclusively by phospholipase A2 but not by hypochlorous acid. Bioorg. Chem. 37, 202-210. doi: 10.1016/j.bioorg.2009.09.002

Schröter, J., and Schiller, J. (2016). Chlorinated phospholipids and fatty acids: (patho)physiological relevance, potential toxicity, and analysis of lipid chlorohydrins. Oxid. Med. Cell. Longev. 2016:8386362. doi: 10.1155/2016/ 8386362

Siddharth, J., Chakrabarti, A., Pannérec, A., Karaz, S., Morin-Rivron, D., Masoodi, M., et al. (2017). Aging and sarcopenia associate with specific interactions between gut microbes, serum biomarkers and host physiology in rats. Aging (Albany NY) 9, 1698-1720. doi: 10.18632/aging.101262

So, I., Chae, M. R., Kim, S. J., and Lee, S. W. (2005). Lysophosphatidylcholine, a component of atherogenic lipoproteins, induces the change of calcium mobilization via TRPC ion channels in cultured human corporal smooth muscle cells. Int. J. Impot. Res. 17, 475-483. doi: 10.1038/sj.ijir.3901356

Soininen, P., Oörni, K., Maaheimo, H., Laatikainen, R., Kovanen, P. T., Kaski, K., et al. (2007). 1H NMR at $800 \mathrm{MHz}$ facilitates detailed phospholipid follow-up during atherogenic modifications in low density lipoproteins. Biochem. Biophys. Res. Commun. 360, 290-294. doi: 10.1016/j.bbrc.2007.06.058

Stefan, N., Häring, H. U., and Cusi, K. (2019). Non-alcoholic fatty liver disease: causes, diagnosis, cardiometabolic consequences, and treatment strategies. Lancet Diab. Endocrinol. 7, 313-324. doi: 10.1016/S2213-8587(18)30154-2

Sugasini, D., and Subbaiah, P. V. (2017). Rate of acyl migration in lysophosphatidylcholine (LPC) is dependent upon the nature of the acyl group. Greater stability of sn-2 docosahexaenoyl LPC compared to the more saturated LPC species. PLoS One 12:e0187826. doi: 10.1371/journal.pone.0187826

Sun, G. Y., Chuang, D. Y., Zong, Y., Jiang, J., Lee, J. C., Gu, Z., et al. (2014). Role of cytosolic phospholipase A2 in oxidative and inflammatory signaling pathways in different cell types in the central nervous system. Mol. Neurobiol. 50, 6-14. doi: 10.1007/s12035-014-8662-4

Takeshima, T., Usui, K., Mori, K., Asai, T., Yasuda, K., Kuroda, S., et al. (2020). Oxidative stress and male infertility. Reprod. Med. Biol. 20, 41-52. doi: 10.1002/ rmb2.12353

Tan, S. T., Ramesh, T., Toh, X. R., and Nguyen, L. N. (2020). Emerging roles of lysophospholipids in health and disease. Prog. Lipid Res. 80:101068. doi: 10.1016/j.plipres.2020.101068

Tanaka, N., Matsubara, T., Krausz, K. W., Patterson, A. D., and Gonzalez, F. J. (2012). Disruption of phospholipid and bile acid homeostasis in mice with nonalcoholic steatohepatitis. Hepatology 56, 118-129. doi: 10.1002/hep.25630

Taylor, L. A., Arends, J., Hodina, A. K., Unger, C., and Massing, U. (2007). Plasma lyso-phosphatidylcholine concentration is decreased in cancer patients with weight loss and activated inflammatory status. Lipids Health Dis. 6:17. doi: 10.1186/1476-511X-6-17 
Wealleans, A. L., Buyse, J., Scholey, D., Van Campenhout, L., Burton, E., Di Benedetto, M., et al. (2020). Lysolecithin, but not lecithin, improves nutrient digestibility and growth rates in young broilers. Br. Poult. Sci. 61, 414-423. doi: 10.1080/00071668.2020.1736514

Xu, H., Valenzuela, N., Fai, S., Figeys, D., and Bennett, S. A. (2013). Targeted lipidomics - advances in profiling lysophosphocholine and plateletactivating factor second messengers. FEBS J. 280, 5652-5667. doi: 10.1111/febs. 12423

Yalagala, P. C. R., Sugasini, D., Dasarathi, S., Pahan, K., and Subbaiah, P. V. (2019). Dietary lysophosphatidylcholine-EPA enriches both EPA and DHA in the brain: potential treatment for depression. J. Lipid Res. 60, 566-578. doi: 10.1194/jlr.M090464

Yatomi, Y., Kurano, M., Ikeda, H., Igarashi, K., Kano, K., and Aoki, J. (2018). Lysophospholipids in laboratory medicine. Proc. Jpn. Acad. Ser. B Phys. Biol. Sci. 94, 373-389. doi: 10.2183/pjab.94.025

Ye, X. (2008). Lysophospholipid signaling in the function and pathology of the reproductive system. Hum. Reprod. Update 14, 519-536. doi: 10.1093/humupd/ dmn023

Zheng, L., Fleith, M., Giuffrida, F., O’Neill, B. V., and Schneider, N. (2019). Dietary polar lipids and cognitive development: a narrative review. Adv. Nutr. 10, 1163-1176. doi: 10.1093/advances/nmz051
Zou, Y., Kim, D. H., Jung, K. J., Heo, H. S., Kim, C. H., Baik, H. S., et al. (2009). Lysophosphatidylcholine enhances oxidative stress via the 5-lipoxygenase pathway in rat aorta during aging. Rejuvenation Res. 12, 15-24. doi: 10.1089/ rej. 2008.0807

Conflict of Interest: The authors declare that the research was conducted in the absence of any commercial or financial relationships that could be construed as a potential conflict of interest.

Publisher's Note: All claims expressed in this article are solely those of the authors and do not necessarily represent those of their affiliated organizations, or those of the publisher, the editors and the reviewers. Any product that may be evaluated in this article, or claim that may be made by its manufacturer, is not guaranteed or endorsed by the publisher.

Copyright $\odot 2021$ Engel, Schiller, Galuska and Fuchs. This is an open-access article distributed under the terms of the Creative Commons Attribution License (CC BY). The use, distribution or reproduction in other forums is permitted, provided the original author(s) and the copyright owner(s) are credited and that the original publication in this journal is cited, in accordance with accepted academic practice. No use, distribution or reproduction is permitted which does not comply with these terms. 